\title{
Endoscopic removal of a partial denture lodged in the jejunum, using single balloon enteroscopy
}

A 48-year-old man accidentally swallowed his upper partial denture while asleep, at about 4 o'clock in the morning. He thought he was dreaming and continued to sleep. However, when he woke up around 7 o'clock, he realized that he was missing his upper denture, and 1 hour later, he presented to our emergency room. A plain film of the abdomen confirmed his fear ( Fig.1). On physical examina- tion the patient appeared poorly groomed and disheveled but in no apparent distress. The abdomen was soft and nontender, and bowel sounds were normal. An esophagogastroduodenoscopy (EGD) did not reveal any foreign body in the entire stomach or duodenum. Thus we carried out a small-bowel enteroscopy, using the single balloon technique (i.e., only using the overtube balloon but not placing a
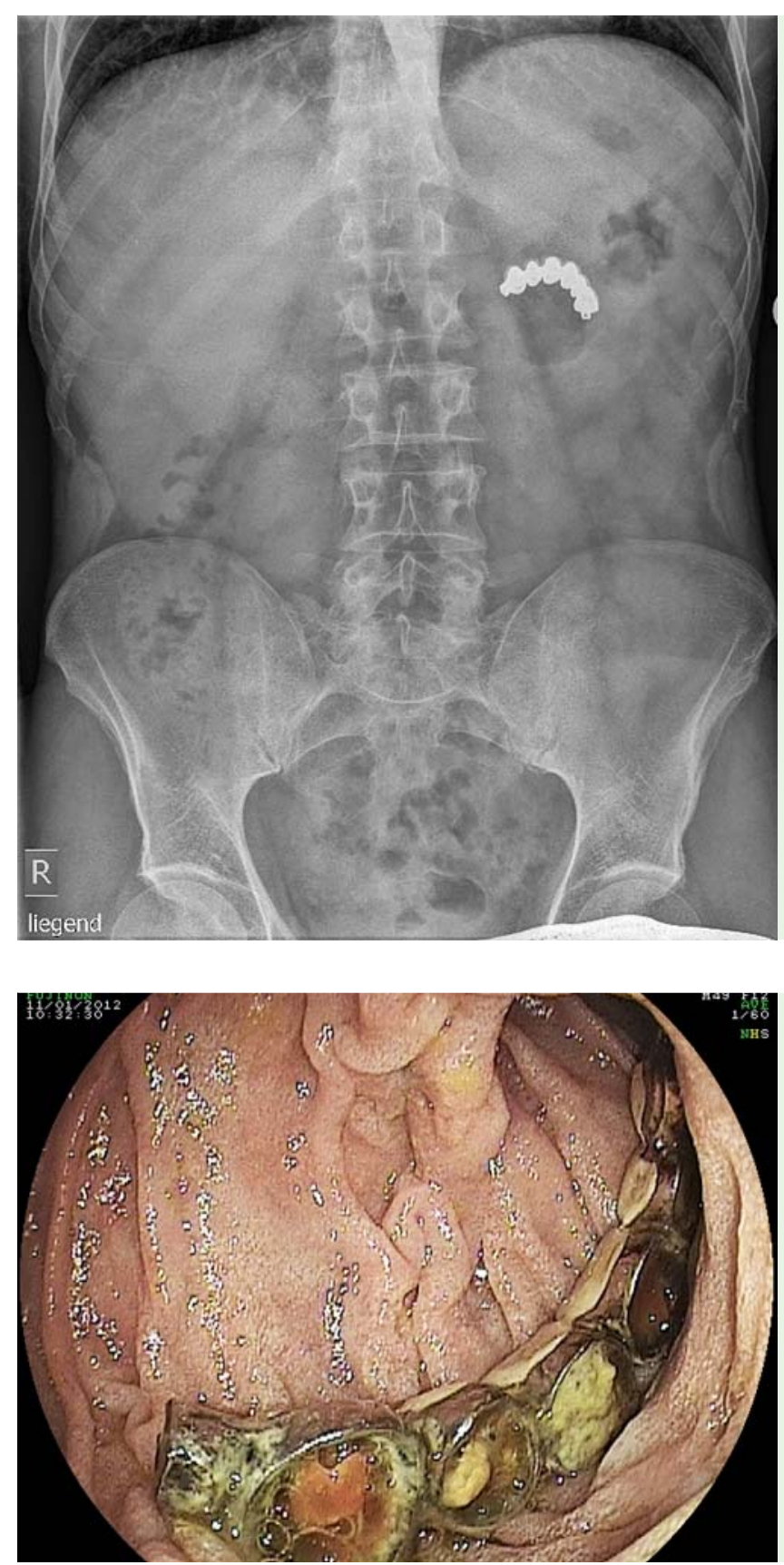

Fig. 1 Abdominal radiograph in a 48-yearold man who accidentally swallowed his upper partial denture while sleeping.

Fig. 2 On small-bowel enteroscopy the denture was found in the jejunum, about $35 \mathrm{~cm}$ from the pylorus. balloon on the scope; Fujinon EN-450T5; Fuji, Fujinon Corp., Tokyo, Japan). The missing denture was found at approximately $35 \mathrm{~cm}$ from the pylorus ( Fig. 2). The overtube was advanced towards the tip of the endoscope, and the balloon of the overtube was inflated to provide stability to the small bowel. With an assistant holding the overtube in a straight position, we could easily torque and manipulate the scope in a to-and-fro manner. Once an adequate endoscopic position was achieved, we used a standard oval snare ( $\bullet$ Fig. 3 a) to grasp the most proximal part of the denture ( $\bullet$ Fig. $\mathbf{3 b}$ ), which was then pulled out under direct and continuous endoscopic visualization. As the denture could not be brought inside the overtube, we proceeded in the following stepwise fashion: (1) we kept the tip of the overtube close to the tip of the enteroscope; (2) the balloon of the overtube was inflated and deflated while pulling out of small bowel; and (3) we kept insufflating the small bowel. We speculated that with this method, the dilated bowel lumen on the proximal side (overtube and partially inflated balloon) and on the distal side (dilated through air insufflation) would minimize impaction and/or laceration potential of the prosthesis while it was being pulled out. Whereas in the stomach there was a minimal chance of impaction, at the level of the cardia and esophageal sphincter we again carefully inflated and deflated the balloon of the overtube to repeat the maneuver used within the small bow-
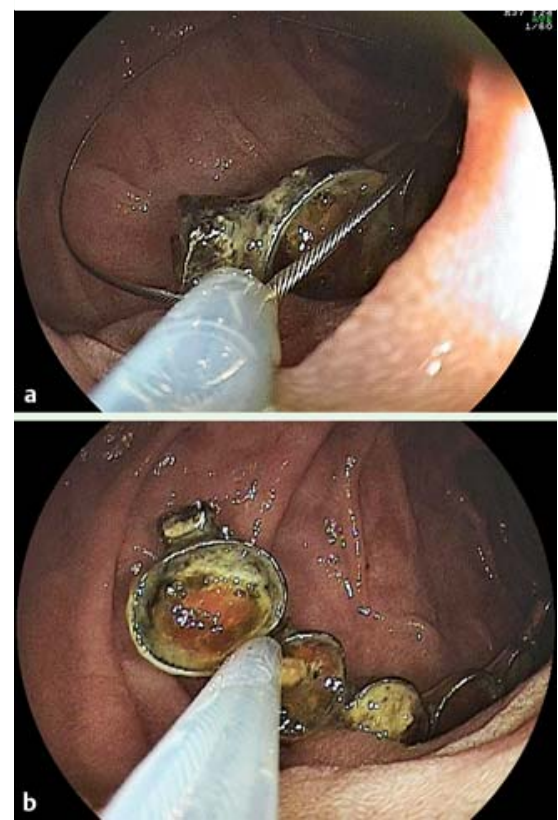

Fig. 3 a, b A standard oval snare being used to grasp and pull out the denture. 
el. The denture was thus successfully removed and returned to the patient, who had it re-cemented by his dentist after discharge.

Most ingested foreign bodies are excreted without any problems. However, large or sharp objects can result in significant complications, such as bowel perforation or an abscess [1]. Dental prostheses are usually large objects, which can get stuck in any part or stricture of the luminal gastrointestinal tract and result in obstruction, fistulae, abscess, perforation, or bleeding [2-4]. Thus, in the present patient, removal of the denture while it was still in the stomach would have been indicated but it had already migrated into the small bowel. Although the most common foreign bodies removed from the small bowel are retained capsule endoscopes, needles, coins, and migrated gastric bands have also been removed using balloon enteroscopy [5-8]. This case report is interesting for several reasons. First, we demonstrated that a large denture with six teeth can be removed endoscopically from the small bowel. Second, we have provided a detailed description of the technical procedure, which may facilitate further use of the procedure. Third, our report adds to the expanding literature on therapeutic small-bowel endoscopy. Lastly, the ready availability of deep enteroscopy techniques allowed us to make rapid decisions, switch equipment and scopes with minimal time delay and con- tinue the search for the lost foreign body within the small bowel. In the absence of deep enteroscopy equipment, we recommend transferring the patient as soon as possible to the closest center with this capability as endoscopy may obviate a stressful "wait-and-watch" strategy, a major complication, or the need for a more invasive procedure such as a laparotomy.

Endoscopy_UCTN_Code_TTT_1AP_2AD

\section{Competing interests: None}

\section{C. Fry ${ }^{1,2}$, Q. Akbar ${ }^{1}$, C. von Gruchalla',}

\section{K. Mönkemüller ${ }^{1,2}$}

${ }^{1}$ Department of Internal Medicine,

Gastroenterology, and Infectious

Diseases, Marienhospital Bottrop,

Germany

2 Otto-von-Guericke University, Magdeburg, Germany

\section{References}

1 Mönkemüller KE, Patil R, Marino CR. Endoscopic removal of a toothpick from the transverse colon. Am J Gastroenterol 1996; 91: $2438-2439$

2 Bunni J, Youssef F. Swallowed dental bridge perforating the terminal ileum. South Med J 2010; 103: 593 - 594

3 Leff DR, Willis A, Menzies D. Dentures in a small-bowel stricture. J R Soc Med 2004; 97: 206-207
4 Sejdinaj I, Powers RC. Enterocolonic fistula from swallowed denture. JAMA 1973; 225 : 994

5 Aktas H, Mensink PB. Therapeutic balloonassisted enteroscopy. Dig Dis 2008; 26: 309-313

6 Safatle-Ribeiro AV, Couto DS Jr, Ferreira de Souza $T$ et al. Single-balloon endoscopy for removing a foreign body in the small bowel (with video). Gastrointest Endosc 2009; 70: $781-782$

7 Neumann H, Fry LC, Rickes S et al. A "doubleballoon enteroscopy worth the money": endoscopic removal of a coin lodged in the small bowel. Dig Dis 2008; 26: 388 - 389

8 Jeon SR, Kim JO, Kim HG et al. Migrated anchoring gastric band removed by doubleballoon enteroscopy. Gastrointest Endosc 2011; 74: 225-227

\section{Bibliography}

DOI http://dx.doi.org/

10.1055/s-0032-1308929

Endoscopy 2012; 44: E236-E237

(c) Georg Thieme Verlag KG

Stuttgart · New York

ISSN 0013-726X

\section{Corresponding author}

\section{K. Mönkemüller}

Department of Internal Medicine,

Gastroenterology, and Infectious Diseases

Marienhospital Bottrop

Josef-Albers-Str. 70

46236 Bottrop

Germany

Fax: +49 20411061019

moenkemueller@yahoo.com 